\title{
PENGETAHUAN KELUARGA DALAM PENGASUHAN DAN TUMBUH KEMBANG ANAK
}

\author{
Iswarati ${ }^{1}$ \\ ${ }^{1}$ Pusat Penelitian dan Pengembangan KB dan Kesehatan Reproduksi, BKKBN
}

\section{ABSTRACT}

\section{FAMILIES' KNOWLEDGE ON CHILD NURTURING, GROWTH AND DEVELOPMENT}

Human capital development in Indonesia is conducted within the framework of an individual's life cycle, starting from the womb until old age. A child grows and develops under the nurture and care of the parents, therefore parents are the foundation of a child's personality development. The 2009 Survey on Child Growth and Development was a national survey designed to establish a provincial level estimate. This survey was conducted in Indonesia's 33 provinces. The goal of the survey was to identify families' knowledge on how to nurture their children in terms of physical, mental and social development. There were 35,478 people surveyed, with $65.2 \%$ living in rural areas and $34.8 \%$ were urban population. The majority of respondents were women $(80.6 \%)$. The research indicates that families' knowledge in terms of child nurturing were not as expected.The knowledge on how to nurture children from a physical aspect has the highest index score of 66.8 , followed by spiritual and social nurturing with an index score of 59.2, and the mental and psychological aspect with an index score of 40.7. The national average of the composite index score was 55.5 with the highest being Central Java province (62) and the lowest being North Maluku (46.3). Better coordination among all related programs is essential in improving efficiency and effectiveness of the programs. Advocacy and socialisation are needed to build public support for the programs.

Keywords: family, child nurture, growth and development, national survey

\section{PENDAHULUAN}

U paya peningkatan kualitas sumber daya manusia berawal dari kehidupan prenatal, terutama sejak awal kehamilan ${ }^{1}$. Status gizi sangat penting bagi ibu terutama sebelum dan saat kehamilan, karena berkaitan dengan kualitas bayi yang akan dilahirkan. Selain itu kualitas ibu setelah melahirkan juga akan berdampak pada kualitas perawatan dan pengasuhan bayi yang telah dilahirkan. Jadi dalam keluargalah masa emas pertumbuhan dan perkembangan anak (the golden years) terjadi, yaitu suatu "periode emas" dalam proses tumbuh kembang seorang anak. Periode emas merupakan faktor kunci terhadap pertumbuhan dan perkembangan anak yang sangat menentukan masa depannya. Hal ini bisa terjadi bila anak berada dalam lingkungan keluarga yang menerapkan pola pengasuhan anak dengan baik.

Pada kenyataannya yang terjadi secara umum di kehidupan masyarakat kita sehari-hari adalah adanya keterbatasan pengetahuan dan pengalaman orang tua dalam membangun lingkungan pengasuhan yang kondusif untuk mengoptimalkan periode emas anak ini. Umumnya kesadaran orang tua untuk meningkatkan fungsi dan peran keluarga dalam pengasuhan anak masih rendah, mereka beranggapan bahwa mengasuh anak berlangsung secara alami dan tidak perlu dipelajari. Pemahaman seperti ini harus diluruskan, karena pengasuhan anak merupakan hal yang sangat penting yang dapat memengaruhi terbentuknya kepribadian seorang anak. Mengacu pada tahap perkembangan kepribadian yang dikembangkan oleh Erikson ${ }^{2}$, konsep diri individu terbentuk pada usia 2-3 tahun dan merupakan dasar perkembangan kepribadian seorang individu untuk seumur hidupnya. Penelitian ini bertujuan untuk mengidentifikasi pengetahuan keluarga tentang cara pengasuhan dan tumbuh kembang anak dari aspek fisik, jiwa, dan sosial.

\section{METODE PENELITIAN}

Desain, lokasi, dan sampel penelitian

Penelitian ini dilakukan di 33 provinsi di Indonesia dan dilaksanakan pada tahun 2009. Responden berjumlah 35478 keluarga, 65,2 persen bertempat tinggal di perdesaan dan yang tinggal di perkotaan 34,8 persen. Responden sebagian besar perempuan $(80,6$ persen) dan laki-laki (19,4 persen). Kerangka 
sampel yang digunakan dibedakan menurut tahapan pemilihan unit sampling, yaitu kerangka sampel untuk pemilihan klaster (Rukun Tetangga/RT) dan kerangka sampel untuk pemilihan keluarga. Dalam pemilihan klaster, terlebih dahulu ditentukan besar sampel di setiap provinsi, kemudian ditentukan banyaknya klaster dan penyebaran klaster secara random ke seluruh provinsi. Kerangka sampel yang digunakan adalah Pendataan Keluarga (R///KS) oleh BKKBN dan disesuaikan dengan data master file desa yang terdapat di BPS. Untuk rancangan sampling, langkah pertama yang dilakukan adalah menghitung jumlah klaster yang diperlukan di setiap provinsi, kemudian menentukan letak klaster terpilih dengan metode Probability Proportionate to Size (PPS). Tahap selanjutnya adalah memilih sejumlah keluarga di setiap klaster terpilih secara sistematik. Jumlah keluarga di setiap klaster terpilih ditentukan sebanyak 25 keluarga.

\section{Data yang dikumpulkan}

Informasi yang dikumpulkan mencakup pengetahuan keluarga tentang pengasuhan dan tumbuh kembang anak dari aspek fisik, jiwa, dan sosial. Data dikumpulkan dengan melakukan wawancara terhadap keluarga melalui daftar pertanyaan yang sudah dipersiapkan terlebih dahulu dan bersifat pertanyaan tertutup.

\section{Pengolahan dan analisis data}

Setelah data terkumpul, dilakutan editing data dan entry data, kemudian dilakukan pengolahan data dengan SPSS. Analisis data dilakukan dengan dua cara. Pertama, melakukan analisis univariat untuk menjelaskan atau mendiskripsikan variabel-variabel yang digunakan dalam penelitian. Kedua, mengingat pengetahuan tumbuh kembang keluarga terdiri dari beberapa materi, maka dibuat angka tunggal (indeks komposit) yang mencerminkan tingkat pengetahuan keluarga tentang cara pengasuhan dan tumbuh kembang anak.

\section{HASIL}

\section{Karakteristik responden}

Secara nasional, responden keluarga yang berhasil diwawancarai sebanyak 35478 keluarga. Sebagian besar responden keluarga bertempat tinggal di perdesaan (65,2 persen) dan yang tinggal di perkotaan 34,8 persen. Responden sebagian besar perempuan $(80,6$ persen), dan selebihnya laki-laki (19,4 persen). Umumnya responden perempuan dan laki-laki berumur di atas 30 tahun, yaitu masing-masing 80 persen dan 84 persen. Mereka pada umumnya berstatus kawin (90,4 persen), selebihnya cerai mati (7,3 persen) dan cerai hidup (2,4 persen). Bila dilihat dari tingkat pendidikan, menunjukkan bahwa proporsi paling besar responden perempuan maupun laki-laki berpendidikan tamat SD (masing-masing 34,7 persen untuk perempuan dan 30,5 persen untuk laki-laki). Namun demikian pendidikan laki-laki terlihat lebih tinggi dibandingkan perempuan. Sebanyak 25 persen laki-laki berpendidikan tamat SLTA dan 6,7 persen tamat akademi dan perguruan tinggi, sedangkan persentase pada perempuan untuk pendidikan yang sama adalah 20,8 persen dan 5,3 persen.

Apabila dilihat dari status pekerjaan, lakilaki 94,3 persen berstatus bekerja, sementara perempuan jauh lebih rendah, yaitu 50,9 persen. Agama yang dianut oleh sebagian besar anggota keluarga adalah agama Islam (86,7 persen), berikutnya adalah agama Kristen/Katolik 10,4 persen, selebihnya agama Hindu, Budha, dan ajaran agama lainnya.

\section{Pengetahuan keluarga tentang pengasuhan dan tumbuh kembang anak}

Pengasuhan berasal dari kata asuh, yang mempunyai arti menjaga, merawat, dan mendidik anak yang masih kecil. Kerangka konseptual yang dikemukakan UNICEF kemudian dikembangkan oleh Engle et al. $^{4}$ menekankan bahwa tiga komponen, yaitu: makanan, kesehatan, dan asuhan merupakan faktor-faktor yang berperan dalam menunjang pertumbuhan dan perkembangan anak yang optimal. Lebih lanjut Engle et al. mengemukakan bahwa pola asuh meliputi 6 hal, yaitu (1) perhatian/dukungan ibu terhadap anak, (2) pemberian ASI atau makanan pendamping pada anak, (3) rangsangan psikososial pada anak, (4) persiapan dan penyimpanan makanan, (5) praktek kebersihan dan sanitasi lingkungan, dan (6) perawatan anak dalam keadaan sakit seperti mencari pelayanan kesehatan.

Mengacu pada konsep dasar tumbuh kembang anak, maka pengasuhan adalah upaya dari lingkungan agar kebutuhan- 
kebutuhan dasar anak untuk tumbuh kembang (asuh, asih, asah) dapat terpenuhi dengan baik dan benar, sehingga anak dapat tumbuh dan berkembang secara optimal. Namun dalam praktek sehari-hari tidaklah sesederhana itu karena praktek berjalan secara informal, yang tanpa disadari dan disengaja dipengaruhi oleh suasana emosi rumah tangga, baik dalam bentuk hubungan antara orang tua dan anaknya, maupun dengan anggota keluarga lainnya. Semuanya ini akan memberi warna pada praktek pengasuhan anak pada setiap keluarga.

Untuk mengetahui pengetahuan keluarga tentang pengasuhan dan tumbuh kembang anak, pertanyaan yang diajukan kepada responden dari penelitian ini adalah "Sepengetahuan Bapak/lbu, apa saja yang dilakukan supaya anak bisa tumbuh dan berkembang dengan baik dari aspek perkembangan fisik, perkembangan jiwa/mental, dan spiritual/agama". Jawaban tidak dibacakan/diarahkan, tapi merupakan jawaban spontan dari responden.

\section{Pengetahuan cara pengasuhan dan tumbuh kembang anak dari aspek fisik}

Hasil penelitian menunjukkan bahwa dilihat dari aspek perkembangan fisik yang diharapkan agar anak sehat, bisa tumbuh dan berkembang dengan baik, yang banyak disampaikan oleh responden keluarga adalah anak diberi makanan bergizi (72,5 persen), diberi ASI (55,6 persen), anak diimunisasi (51,4 persen), anak ditimbang (42,3 persen), anak diberi vitamin (33,9 persen), dan anak diobati kalau sakit (29,9 persen). Terlihat disini bahwa pengetahuan keluarga dari aspek perkembangan fisik belum cukup banyak diketahui dan dipraktekkan oleh keluarga.

Berkaitan dengan penyediaan makanan bergizi serta pelayanan kesehatan, di mana keluarga mempraktekkan dan mewujudkan dengan tersedianya pangan dan perawatan kesehatan untuk kelangsungan hidup, pertumbuhan dan perkembangan anak merupakan suatu yang tidak mudah. Sebenarnya orang tua mengetahui makanan yang bergizi itu seperti apa, namun keluarga sering terkendala oleh kondisi ekonominya, sehingga tidak bisa memberi makan dan kesehatan seperti yang diharapkan.

Dalam masyarakat Indonesia, wanita dianggap sebagai pihak yang paling bertanggung jawab terhadap kesehatan, pengasuhan dan tumbuh kembang anak. Khususnya untuk anak balita, kesehatan mereka sangat tergantung pada orang yang mengasuhnya, dalam hal ini adalah para ibu. Seringkali kebutuhan dasar anak untuk tumbuh kembang tidak didapatkan anak dengan baik dan benar. Sebagai contoh, hasil penelitian menunjukkan bahwa pemberian ASI relatif masih rendah (56 persen). Peningkatan pengetahuan bagi wanita saja tidaklah cukup untuk dapat meningkatkan kualitas hidup anak, tapi masih perlu adanya dana yang cukup. Terlebih pada keluarga miskin perlu diberikan pemahaman tentang bagaimana wanita sebagai ibu dengan kondisi yang terbatas dapat memenuhi kebutuhan pertumbuhan dan kesehatan anaknya.

\section{Pengetahuan cara pengasuhan dan tumbuh kembang anak dari aspek mental/jiwa}

Untuk aspek perkembangan mental/jiwa, yang diharapkan agar anak merasa aman dan nyaman, yang banyak disampaikan oleh responden keluarga adalah orang tua menemani belajar (51 persen), orang tua menemani bermain ( 45,3 persen), orang tua sebagai teladan/panutan (43,8 persen), orang tua menstimulasi perkembangan anak $(26,9$ persen), dan orang tua tempat curahan hati (27 persen). Pengasuhan dan tumbuh kembang anak dari aspek mental/jiwa menunjukkan bahwa umumnya pengetahuan keluarga relatif masih kurang.

Menurut Puspita 5 , pengasuhan anak merupakan salah satu faktor yang menentukan pertumbuhan dan perkembangan anak, terutama pada masa-masa kritis (0-8 tahun). Kehilangan pengasuhan yang baik, misalnya perceraian, kehilangan orang tua untuk sementara atau selamanya, adanya bencana alam, dan berbagai hal yang bersifat traumatis akan memengaruhi kesehatan fisik dan psikologisnya.

Demikian halnya dengan anak bermain bukan berarti membuang waktu, juga bukan berarti membuat anak menjadi sibuk, sementara orang tuanya mengerjakan pekerjaannya sendiri. Menurut Soetjiningsih ${ }^{6}$ anak harus mempunyai cukup waktu untuk bermain dan untuk bermain diperlukan alat permainan yang sesuai dengan umur dan taraf perkembangannya. Stimulasi merupakan hal yang penting dalam tumbuh kembang anak. 
Anak yang mendapat stimulasi terarah dan teratur akan lebih cepat berkembang dibandingkan dengan anak yang kurang atau tidak mendapat stimulasi. Selain itu motivasi belajar dapat ditimbulkan sejak dini, dengan memberikan lingkungan yang kondusif untuk belajar, serta memberi hukuman yang sesuai merupakan hal yang dapat menimbulkan motivasi yang kuat dalam perkembangan kepribadian anak di kemudian hari.

Ditinjau dari teori Erikson tentang perkembangan psikososial 7 , pada usia prasekolah (sekitar 4-5 tahun) anak diharapkan dapat mengembangkan 'sense of initiative'. Diketahui bahwa masa pra sekolah merupakan masa yang subur untuk pengembangan kreativitas, karena anak pada masa ini mempunyai kreativitas alamiah, akan tetapi potensi kreativitas ini akan hilang jika tidak didukung oleh lingkungan rumah, komunitas dan masyarakat yang memadai. Namun pada kenyataannya masih banyak ibu-ibu yang tingkat pendidikannya rendah, sehingga sulit memberikan stimulasi mental kepada anak. Dalam hal ini yang perlu diupayakan adanya program pengembangan anak pra sekolah yang langsung ditujukan kepada anak antara lain berupa program intervensi, televisi pendidikan, alat permainan edukatif dan kreatif. Selain itu perlu pula dikembangkan program intervensi secara tidak langsung untuk ibu dan ayah, yakni dengan melakukan pembinaan terhadap ibu hamil dan calon ayah, serta pemanfaatan Posyandu.

Hasil studi Zeitlin ${ }^{8}$ untuk balita $0-27$ bulan menunjukkan bahwa orang tua dengan skor pola asuh tinggi mempunyai anak dengan indeks perkembangan mental dan indeks perkembangan fisik yang tinggi pula (berdasarkan skala Bailey untuk perkembangan balita). Oleh karena itu perlu upaya meningkatkan pengetahuan dan keterampilan keluarga untuk menjadi pengasuh yang baik.

Menurut Suryawan ${ }^{9}$, agar anak mempunyai performa yang baik, orang tua harus memberikan nutrisi dan stimulasi yang tepat. Menurutnya nutrisi dan stimulasi harus diberikan sejak dari kandungan, begitu bayi dilahirkan, saat batita, balita, usia sekolah hingga remaja. Nutrisi diperlukan untuk menunjang kemampuan otak dan daya tahan tubuh, sedangkan stimulasi dibutuhkan untuk pengalaman dini anak dan proses tumbuh kembangnya. Masalah yang dihadapi kebanyakan orang tua di Indonesia adalah banyak anak Indonesia yang tidak dapat tumbuh secara optimal akibat penanganan yang tidak tepat karena ketidaktahuan orang tua. Orang tua yang terlalu sibuk bekerja jarang berinteraksi dengan anak-anaknya, mereka lebih mengandalkan pengasuh untuk menstimulasi anak.

\section{Pengetahuan cara pengasuhan dan tumbuh kembang anak dari aspek sosial}

Untuk aspek perkembangan sosial dan spiritual, yang diharapkan adalah anak mampu mandiri, bergaul, rajin beribadah dan berprestasi, yang menonjol disampaikan oleh responden keluarga adalah anak harus disekolahkan (72,1 persen), dan anak harus diajari beribadah (67,9 persen). Sementara proporsi relatif rendah adalah anak diajari berperilaku hidup sehat (34,6 persen), anak diberi kesempatan bermain dengan teman sebaya (29,7 persen), anak dikursuskan (9,9 persen), dan anak diikutsertakan dalam lomba (6,2 persen).

Faktor keluarga yang berpengaruh terhadap tumbuh kembang anak antara lain pekerjaan/penghasilan keluarga. Penghasilan keluarga yang baik akan menunjang tumbuh kembang anak karena orang tua dapat menyediakan semua kebutuhan anak, baik kebutuhan primer (pangan, sandang, kesehatan) maupun kebutuhan sekunder (sekolah, kursus, rekreasi). Pendidikan orang tua yang baik akan lebih mudah menerima informasi dari luar terutama yang berkaitan dengan cara pengasuhan anak yang baik dan menjaga kesehatan.

Untuk proses sosialisasi dengan lingkungannya, anak memerlukan teman sebaya. Orang tua yang memberikan kebebasan anaknya cukup luas cenderung mempunyai anak-anak yang kreatif. Orang tua yang memberi kebebasan tidak selalu mengontrol anaknya dan tidak bersifat restriktif terhadap kegiatan anaknya.

Mencermati cara pengasuhan dan tumbuh kembang anak menurut provinsi sangat bervariasi. Namun secara umum untuk perkembangan fisik, proporsi keluarga yang tidak tahu tertinggi di Maluku Utara (14,5 persen), terendah di Kalimantan Selatan, DKI Jakarta, dan Sulawesi Selatan (masing-masing kurang dari 1 persen). Dilihat dari 
perkembangan mental/jiwa, proporsi keluarga yang tidak tahu terbanyak di Maluku Utara $(25,8$ persen) dan Nusa Tenggara Barat (25,3 persen), sedangkan yang terendah di DKI Jakarta (3,3 persen). Selanjutnya untuk perkembangan sosial dan spiritual anak, proporsi keluarga yang tidak tahu terbanyak ditemukan di Maluku Utara (16,1 persen) hingga proporsi terendah di DKI Jakarta, Lampung, Bangka Belitung, dan Kalimantan Selatan (masing-masing kurang dari 2 persen).

\section{Angka Pengetahuan Keluarga tentang Pengasuhan dan Tumbuh Kembang Anak}

Untuk mendapatkan angka pengetahuan keluarga tentang tumbuh kembang anak, maka dibuat indeks komposit tumbuh kembang anak yang diperoleh dari pengetahuan tentang tumbuh kembang fisik, jiwa/mental anak, dan sosial spiritual anak. Pembobotan untuk aspek fisik dilakukan untuk jawaban anak ditimbang, anak diberi makanan bergizi, anak di imunisasi, anak diberi $\mathrm{ASI}$, anak diberi vitamin, dan anak diobati kalau sakit. Pembobotan untuk aspek jiwa/mental dilakukan untuk jawaban orang tua yang meliputi menstimulasi/memacu anak, orang tua menemani anak bermain, orang tua menemani anak belajar, orang tua tempat curahan hati, dan orang tua sebagai teladan/contoh/panutan. Sedangkan pembobotan untuk aspek sosial dan spiritual/agama dilakukan untuk jawaban orang tua yang meliputi mengajar anak berperilaku hidup sehat sejak kecil, orang tua memberi kesempatan bermain dengan teman sebaya, orang tua mengajar anak beribadah, anak disekolahkan, anak dikursuskan, anak diikutkan dalam lomba, dan anak diikutkan dalam kegiatan sosial.

Rentang indeks berkisar antara 0-100 untuk seluruh provinsi di Indonesia. Perlu diketahui untuk Provinsi Papua Barat dan Papua perlu hati-hati dalam analisa karena data sangat diragukan kualitasnya (outlyer), namun demikian pada tabel masih dicantumkan kedua provinsi tersebut, karena sampel kecil tidak mengganggu atau mempengaruhi angka nasional. Tabel 1 menunjukkan rata-rata setiap keluarga di Indonesia nilai indeks komposit tumbuh kembang anak mencapai 55,5 dari rentang indeks: 0-100. Perbedaan pencapaian antara indeks pengetahuan tumbuh kembang anak tertinggi dengan indeks pengetahuan tumbuh kembang anak terendah sekitar 15,7 poin, dengan rentang tertinggi 62 untuk Provinsi Jawa Tengah dan terendah 46,3 untuk Provinsi Maluku Utara. Tiga provinsi yang rata-rata setiap keluarga nilai indeks komposit tumbuh kembang anak di atas 60 selain Jawa Tengah adalah DKI Jakarta dan Kepulauan Bangka Belitung.

Kewajiban dan tanggung jawab orang tua dan keluarga menurut Undang-Undang nomor 23 tahun 2002 tentang perlindungan anak, antara lain menyangkut mengasuh, memelihara, mendidik, dan melindungi anak serta menumbuh kembangkan anak sesuai dengan kemampuan, bakat dan minatnya. Melihat hasil indeks komposit pengetahuan tumbuh kembang anak relatif belum seperti yang diharapkan, demikian pula variasi antar provinsi juga cukup tinggi. Pengetahuan tumbuh kembang anak yang berkaitan dengan perkembangan fisik terlihat paling banyak diketahui keluarga, yakni dengan rata-rata setiap keluarga secara nasional nilai indeks mencapai 66,8. Disusul kemudian yang berkaitan dengan aspek sosial spiritual dengan rata-rata setiap keluarga di Indonesia nilai indeks mencapai 59,2 dan yang paling sedikit diketahui keluarga adalah perkembangan jiwa/mental anak di mana ratarata setiap keluarga hanya 40,7 . Oleh karena itu pengasuhan dan pengembangan anak secara menyeluruh yang mencakup fisik, sosial, dan mental perlu diperhatikan secara baik, karena sangat menentukan perjalanan hidupnya.

Besar dan pentingnya peran keluarga dalam pembangunan SDM yang berkualitas seringkali tidak diimbangi dengan pengetahuan, pemahaman, dan keterampilan pengasuhan yang memadai. Bagi sebagian besar masyarakat mengasuh anak dianggap sebagai kegiatan rutin dan alamiah yang semua orang bisa melakukannya, jadi mengasuh anak belum dirasakan sebagai keterampilan yang harus dipelajari. Hasil penelitian menunjukkan bahwa terdapat faktor-faktor yang mempengaruhi kualitas pengasuhan anak, antara lain struktur keluarga (keluarga utuh atau cerai), ekonomi, dan kesehatan mental orang tua terutama ibu ${ }^{10}$ (Simons, 1996). Menurut Caldwell dan Bradley ${ }^{11}$, kualitas pengasuhan anak lebih ditentukan oleh lingkungan pengasuhan yang dipraktekkan oleh orang tuanya. 
Tabel 1

Indeks Komposit Pengetahuan Keluarga tentang Pengasuhan dan Tumbuh Kembang Anak menurut Provinsi, Indonesia 2009

(Rentang Indeks: 0-100)

\begin{tabular}{|c|c|c|c|c|}
\hline Provinsi & $\begin{array}{l}\text { Indeks } \\
\text { pengetahuan } \\
\text { tumbuh kembang } \\
\text { fisik anak }\end{array}$ & $\begin{array}{l}\text { Indeks } \\
\text { pengetahuan } \\
\text { tumbuh kembang } \\
\text { jiwa/mental anak }\end{array}$ & $\begin{array}{l}\text { Indeks pengetahuan } \\
\text { tumbuh kembang } \\
\text { sosial-spritual anak }\end{array}$ & $\begin{array}{l}\text { Indeks komposit } \\
\text { pengetahuan tumbuh } \\
\text { kembang anak }\end{array}$ \\
\hline NAD & 68,2 & 42,1 & 59,4 & 56,6 \\
\hline Sumatera Utara & 61,0 & 39,8 & 57,4 & 52,7 \\
\hline Sumatera Barat & 65,6 & 40,2 & 60,4 & 55,4 \\
\hline Riau & 63,8 & 36,7 & 56,5 & 52,3 \\
\hline Jambi & 65,1 & 39,1 & 56,1 & 53,4 \\
\hline Sumatera Selatan & 64,4 & 38,0 & 57,3 & 53,2 \\
\hline Bengkulu & 62,3 & 35,5 & 52,8 & 50,2 \\
\hline Lampung & 68,3 & 44,7 & 60,0 & 57,7 \\
\hline Kepulauan Bangka Belitung & 74,0 & 43,7 & 65,8 & 61,2 \\
\hline Kepulauan Riau & 65,0 & 38,4 & 56,8 & 53,4 \\
\hline DKI Jakarta & 73,9 & 46,1 & 64,2 & 61,4 \\
\hline Jawa Barat & 67,5 & 37,8 & 58,8 & 54,7 \\
\hline Jawa Tengah & 74,0 & 47,4 & 64,5 & 62,0 \\
\hline DI Yogyakarta & 57,5 & 37,6 & 55,1 & 50,1 \\
\hline Jawa Timur & 69,4 & 40,1 & 62,3 & 57,3 \\
\hline Banten & 65,7 & 42,0 & 57,1 & 54,9 \\
\hline Bali & 60,8 & 29,4 & 58,1 & 49,5 \\
\hline Nusa Tenggara Barat & 56,9 & 32,3 & 50,0 & 46,4 \\
\hline Nusa Tenggara Timur & 68,2 & 44,3 & 56,0 & 56,2 \\
\hline Kalimantan Barat & 69,5 & 46,7 & 59,4 & 58,5 \\
\hline Kalimantan Tengah & 63,6 & 41,8 & 56,7 & 54,0 \\
\hline Kalimantan Selatan & 65,4 & 32,2 & 55,5 & 51,0 \\
\hline Kalimantan Timur & 65,6 & 41,6 & 61,5 & 56,2 \\
\hline Sulawesi Utara & 58,4 & 36,6 & 52,8 & 49,3 \\
\hline Sulawesi Tengah & 60,6 & 32,7 & 50,9 & 48,0 \\
\hline Sulawesi Selatan & 65,2 & 43,9 & 60,0 & 56,4 \\
\hline Sulawesi Tenggara & 65,8 & 37,9 & 55,9 & 53,2 \\
\hline Gorontalo & 57,0 & 32,4 & 51,5 & 47,0 \\
\hline Sulawesi Barat & 64,5 & 36,2 & 53,3 & 51,4 \\
\hline Maluku & 62,6 & 44,6 & 59,2 & 55,5 \\
\hline Maluku Utara & 55,6 & 35,1 & 48,1 & 46,3 \\
\hline Papua Barat & 61,0 & 54,6 & 56,7 & 57,5 \\
\hline Papua & 65,4 & 42,0 & 63,9 & 57,1 \\
\hline Indonesia & 66,8 & 40,7 & 59,2 & 55,5 \\
\hline
\end{tabular}




\section{SIMPULAN DAN SARAN}

Hasil penelitian menunjukkan bahwa pengetahuan keluarga tentang pola pengasuhan dan tumbuh kembang anak belum seperti yang diharapkan, baik dari aspek perkembangan fisik, perkembangan jiwa/mental, maupun spiritual/agama. Rata-rata nilai indeks komposit tumbuh kembang anak secara nasional mencapai 55,5 , dengan rentang tertinggi 62 Provinsi Jawa Tengah dan terendah 46,3 Provinsi Maluku Utara. Pengetahuan tumbuh kembang anak yang berkaitan dengan perkembangan fisik terlihat paling banyak diketahui keluarga daripada perkembangan jiwa/mental dan spiritual.

Pengetahuan dan praktek tumbuh kembang anak yang berkaitan dengan perkembangan fisik terlihat paling banyak diketahui keluarga, yakni dengan nilai indeks rata-rata secara nasional 66,8 , yang berkaitan dengan aspek sosial spiritual dengan nilai indeks rata-rata 59,2 , dan perkembangan jiwa/mental hanya 40,7 .

Perlu koordinasi yang lebih baik dari berbagai program yang berkaitan dengan pengasuhan dan tumbuh kembang anak dalam rangka meningkatkan efektifitas dan efisiensi program-program tersebut. Penyelenggaraan pengasuhan dan pengembangan anak usia dini saat ini masih tersebar di sejumlah instansi, seperti Kementerian Diknas (PAUD), Kementerian Agama (Raudhatul Athfal/RA), Kementerian Kesehatan, Kementerian Dagri (Posyandu), Kementerian PP, dan BKKBN. Selain itu, advokasi dan desiminasi program pengasuhan dan tumbuh kembang anak perlu ditingkatkan untuk membangun dukungan masyarakat dan menyebarluaskan ke seluruh masyarakat.

Dalam pembinaan anak, peran ibu merupakan peran kunci dan tak tergantikan oleh siapapun dan oleh lembaga manapun, sejak saat hamil, melahirkan, pengasuhan pada masa bayi, pra sekolah, masa sekolah, dan masa remaja. Untuk itu perlu pembinaan tingkat kesejahteraan dan keselamatan ibu yang secara kodrati berkaitan dengan kesehatan reproduksi.

\section{RUJUKAN}

1. UNICEF. Memaksimalkan Potensi Sumber Daya Manusia Indonesia. Sebuah
Pendekatan Bertumpu pada Resiko di Keluarga, Kebutuhan, dan Hak-haknya dalam Rangka Menentukan Prioritas dan Strategi Repelita VII. Jakarta: BKKBN, 1997.

2. Sunarti, E. Peran Keluarga dalam Pengasuhan Anak. Paper disampaikan pada Seminar Hari Keluarga Nasional Tahun 2006. Bogor,: Pemda Kabupaten

3. Eagle et. al. Care and Nutrition: Concepts and Measurement. S.I: International Food Policy Research Institute, 1997.

4. Sunarwati. Praktek Pengasuhan dalam Menyiapkan Anak Berkualitas. 2009. http://nurulfikri.sch.id/index.php tanggal 4 Agustus 2010.

5. Puspita. Pengasuhan Anak. 2008. http://pptapaksuci.org/index.php/indonesial rubrik-umum/keluarga/pengasuhananak.html tanggal 12 November 2010.

6. Soetjiningsih. Tumbuh Kembang Anak. 1995. http://repository.USU.ac.id/ bidstream) tanggal 9 November 2010.

7. Munandar, S.C. Utami. Determinan NonMedis, Perilaku dan Masyarakat dalam Perkembangan Masa Anak. Dalam Prosiding Lokakarya Nasional Masalah Pengukuran, Pencapaian Intervensi Terfokus terhadap Kesejahteraan Ibu dan Tumbuh Kembang Anak dalam Konteks Pembangunan Sumberdaya Manusia di Indonesia. Jakarta: LIPI, BPS, UNICEF. 1997.

8. Zeitlin, Marian. Peran Pola Asuh Anak: Pemanfaatan Hasil Studi Penyimpangan Positif untuk Program Gizi. Dalam Prosiding Widyakarya Nasional Pangan dan Gizi VII Tahun 2000. LIPI. Jakarta: LIPI, 2000.

9. Suryawan. Orang Tua Indonesia Masih "Gagap" dalam Pola Asuh Anak. Diunduh dari http://www.go4healthylife.com/articles tanggal 21 Agustus 2010.

10. Simon and Associates. Understanding Differences Between Divorced and Infact Families: Stress, Interaction, and Child Outcome. California: Sage Publications, 1996.

11. Caldwell, B.M and Bradley, R.H. Administration Manual: Home Observation for Measurement of the Environment. Revised edition. Arkansas: University of Arkansas, 1984. 
